\title{
Küresel Karbondioksit Emisyonu, Ekonomik Büyüme ve Elektrik Tüketiminin Hiyerarşik Yapı Yöntemleri Kullanılarak Topolojik Analizi
}

\author{
Şeyma Akkaya Deviren ${ }^{1, *}$ \\ ${ }^{1}$ Nevşehir Hacı Bektaş Veli Üniversitesi, Ĕgitim Fakültesi, İlköğretim Fen Bilgisi Anabilim Dalı, Nevşehir \\ Özet \\ Bu çalışmada, sosyofizik kapsamında yirmibeş Avrupa ülkesinin çevre kirlilikleri, ekonomik büyümeleri ve elektrik tüketimleri \\ arasındaki topolojik ilişsiler hiyerarşik yapı yöntemleri [en küçük örten ağaç (minimal spanning tree, MST) ve hiyerarşik ağaç \\ (hierarchical tree, HT)] kullanılarak 1970 ile 2010 yılları arasında detaylıca incelenmiștir. MST ve HT'ler verilerdeki hiyerarşiyi, \\ sınıflandırmayı ve küresel yapıyı tespit etmek ve anlamak için kullanışlı seçeneklerdir. Ekonomik, sosyal, jeolojik ilişkilerine ve \\ yakınlıklarına göre MST'lerden ve HT'lerden farklı kümeler tanımlanıp ve çevre kirliliği, ekonomik büyüme ve elektrik tüketimleri \\ arasındaki ilişkiler belirlenmiştir. Böylece küme yapıları ve her bir kümedeki anahtar ülke/ülkeler de tespit edilmiştir.
}

Anahtar kelimeler: Sosyofizik, hiyerarşik yapı yöntemleri, $\mathrm{CO}_{2}$ emisyonu, ekonomik büyüme, elektrik tüketimi

\section{Topological Analysis Among Carbon dioxide Emission, Economic Growth and Electricity Consumption by Using Hierarchical Structure Methods}

\begin{abstract}
In this study, within the scope of sociophysics, the topological relationships among the CO2 emissions, per capita of Gross Domestic Product (GDP) and electricity consumptions are investigated by using the concept of hierarchical structure methods (minimal spanning tree (MST) and hierarchical tree (HT)) for 25 European countries over the period of 1970-2010. The MST and HT are useful tools for understanding and detecting the global structure, taxonomy and hierarchy in data. From the MSTs and HTs different clusters of countries are identified according to their proximity, economic/social/geological ties, and the relation among countries are determined. Hence, the clustered structure of the countries and the key country/countries in each cluster are detected.
\end{abstract}

Keywords: Sociophysics, hierarchical structure methods, $\mathrm{CO}_{2}$ emissions, economic growth, electricity consumptions

\footnotetext{
*e-mail: sadeviren@nevsehir.edu.tr
} 
Akkaya-Deviren Ş.

1. Giriş

Sosyofizik, bazı teorik fizik, uygulamalı matematik ve kompleksite metotlarının uygulanması ile sosyal sistemlere ve sosyal problemlere çözüm getiren ve problemleri inceleyen disiplinler arası bir araştırma alanıdır. Dahası sosyofizik, yeni bir interdisipliner (disiplinler arası), multidisipliner (çok disiplinli) ve transdisipliner (disiplinler ötesi) bilimin doğuşunu temsil etmektedir. Callen ve Shapiro [1] tarafindan yazılan ve Physics Today dergisinde yayınlanan balık grupları, benzerlik ve Ising spinleri hakkında yazılan "A theory of social imitiation" başlıklı makale ve Weidlich [2] tarafından yazılan ve Br. J. Math. Statist. Psychol. adlı dergide yayınlanan düşünce biçimlenişinin dinamiği konusunun tartış1ldığ1 "The statistical description of polarization phenomena in society" başlıklı makaleler sosyofiziğin kuruluşunun ilk adımları olarak kabul edilir.

Çok uzun bir dönem az sayıda fizikçi dışında pek çok fizikçi bu konuya gereken ilgiyi göstermedi. Çünkü başlangıçta bırakın diğer bilim ve araştırma alanlarında çalışanları, fizikçiler arasında da yaygın olarak "sosyal ve politik olayların ve olguların modellenemeyeceği", bunların "fizik modellerinin geliştirilemeyeceği" düşüncesi ile "bu konuların fizikle ne ilgisi var", "bırakın bunları fizikle ilgilenin" şeklinde gösterilen tepkiler hakimdi. Ancak son birkaç yılda sosyal ve politik olayların başarılı fiziksel modellerinin yapılması sonucunda bugün sosyofizik, fiziğin ve özellikle istatistiksel fiziğin yeni bir uygulama alanı olarak kabul görmüştür. Bu kısa dönem içinde çok sayıda sosyal, toplumsal fenomen (görüngü) ele alındı ve bunlar için modeller geliştirildi. Bu başarıların ardından sosyofizik alanında şaşırtıcı bir ilgi patlaması yaşandı. Dünyada bu alana ilgi giderek artmaktadır. Bunun en iyi kanıtı; son aylarda en saygın fizik dergilerinde (Physical Review E, Physical Review Letters, Europhysics Letters, Journal of Statistical Mechanics, Physica A, Computer Physics Communications, International Journal of Modern Physics C ve The Journal of Artificial Societies and Social Simulation) sosyofizik çalışmalarına dikkate değer ölçüde yer verilmesidir. Gerçektende giderek artmakla birlikte her ay yaklaşık elli sosyofizik çalışması uluslararası indeksli dergilerde yayınlanmaktadır [3]. Örneğin Polonyalı fizikçi Krzysztof Kulakowski, 2007 yılındaki Sosyo-Econo-Fizik isimli yaz okulunun ardından yayınlanan kitapta, sosyofizik ve sosyoloji arasındaki köprü olarak Fransız Fizikçi Serge Galam’ı ifade etmiş ve sosyofizik alanında önde gelen yazarlarından birisi olarak tanımlamıştır [4]. Serge Galam'ın “İnsanlarda atomlar gibi davranırlar” ifadesine hem katı bilimlere hemde insan karmaşıklığına bir küfür, bir saçmalık ve kınanması gereken bir şey gözüyle bakılmıştır. Bundan dolayı sosyofizik son on beş yıl boyunca mahkûm edilmiştir." diye ifade etmiştir [5] ve 2012 yılında basılan Sociophysics isimli kitabında bunları daha kapsamlı olarak ifade etmiştir [6].

Sosyal sistemlerde incelenen varlıklar arasındaki ilişkiler bu varlıklar arasındaki korelasyon ağları kullanılarak aydınlatılır ve bunlar sosyal sistemlerin analizi için faydalıdırlar. Örneğin ekonofizik'te mevcut mal değerlerinin (stocks prices) ve borsa değerlerinin (market prices) çiftleri arasındaki korelasyonlar hesaplanarak bunların hiyerarşik sınıflandırması hiyerarşik yapı yöntemleri ile kapsamlıca incelenmektedir. Bu çalışmalardan ilk olarak Mantegna [7] finansal piyasalardaki hiyerarşik yapıları ayrıntılı olarak incelemiştir. Ayrıca, finansal varlık çiftleri arasındaki korelasyon ilişkisi, Mantegna ve Stanley [8] taraflarından ekonofizik ile ilgili yazdıkları kitapta kapsamlıca verilmişstir. Bu çalışmada hisse senetlerini ve kümelenme davranışını, tek bir ülkedeki (İtalya) stokları kullanarak incelemişlerdir. Bonanno ve arkadaşları [9] ABD'de, New York Menkul Kıymetler borsasında (NYSE) 
işlem gören hisse senedi çiftleri arasındaki korelasyonları incelemiştir. Yine stoklar arası korelasyonların en küçük örten ağaç (MST) kullanılarak incelenmesi, Zherebtsov ve Kuperin [10] tarafından yapılmıştır. Eom ve arkadaşları [11] MST yöntemiyle S\&P 500 stock market index (S\&P500) ve Korea Composite Stock Price Index'de (KOSPI) listelenen hisse senedi getirilerini kullanarak belirli bir hisse senedinin bağlantı sayısını etkileyen faktörü araştırmışlardır. Garas ve Argyrakis [12] MST yöntemini ve rastgele matris teorisi (RMT) yöntemini kullanarak 1987-2004 zaman periyodunda Atina Menkul Kiymetler Borsasında (ASE) işlem gören üç farklı portföyün özelliklerini araştırmışlardır. Bununla birlikte, Garas ve arkadaşları [13] bir mali piyasa ağında zayıf ve güçlü şebeke bağlarının yapısal rolünü araştırmışlardır. Ayrıca, Çukur ve arkadaşları [14] RMT yöntemini kullanarak İstanbul Menkul Kıymetler Borsasındaki (IMKB) finansal verilerin çapraz korelasyonlarını hesaplamışlardır. Avrupa hisse senedi piyasaları üzerine ise, Gilmore ve arkadaşları [15] yirmibir farklı Avrupa Birliği borsa endeksi için ortak hareketler sürecini MST kullanarak incelemişlerdir. Sieczka ve Hołyst [16], 1998-2007 zaman periyotlarında emtia (commodity) piyasaları için analiz yapmışlardır. Ayrıca, Brida ve arkadaşları [17] hiyerarşik yapı yöntemlerini kullanarak İspanya'daki uluslararası otelcilik endüstrisini incelemişlerdir. Spada ve arkadaşları [18] ise MST'leri kullanarak hepatit C virüs enfeksiyonunu incelemişlerdir. MST ve hiyerarşik ağaç (HT) yöntemleri aynı zamanda para piyasalarını analiz etmek ve özellikle para birimlerinin kümelenme yapısını ve her kümedeki anahtar para birimini bulmak için de kullanılmıştır. Mizuno ve arkadaşları [19] döviz piyasasındaki çeşitli para birimlerinin verilerini analiz ederek para birimlerinin hiyerarşik sınıflandırmasını yapmışlardır. Bunlar, dünya döviz piyasasına yön veren büyük ekonomilerin para birimlerinin hiyerarşik sınıflandırmada kilit rol oynadıklarını ve hiyerarşik yapılarda merkezde yer aldıklarını göstermişlerdir. Naylor ve arkadaşları [20] MST ve HT yöntemlerini kullanarak önemli para birimlerinin topolojik analizini 1995-2001 yılları için incelemişlerdir. Piyasaların kriz süresi boyunca kararlı davrandığını göstermişlerdir. Keskin ve arkadaşları [21] hiyerarşik yapı yöntemlerini kullanarak Türk Lirası (TL) dahil önemli para birimleri arasındaki korelasyon ilişkisinin topolojisini, 2007, 2008 ve 2007-2008 yılları için incelemişlerdir. Bununla birlikte Keskin ve arkadaşları [22] IMKB'de işlem gören önemli Türk şirketleri arasındaki ilişkileride incelemişlerdir. Kocakaplan ve arkadaşları [23] Türkiye'nin ithalat ve ihracatında kullanılan TL dâhil önemli para birimleri arasındaki ilişkileri 1996-2010 yılları için incelemiş̧lerdir. Kantar ve arkadaşları [24] Türkiye'nin ticaret yaptığı ülkeler arasındaki ilişkileri kapsamlıca analiz etmişlerdir. Ayrıca aynı grup önemli 18 Türk ve 80 uluslararası şirketin hiyerarşik yapısını hiyerarşik yapı yöntemleri kullanarak incelemişler ve benzer şirket gruplarının, özellikle banka ve otomotiv sanayi şirketlerinin, birbiriyle kuvvetli bir şekilde ilişkili olduklarını ifade etmişlerdir [25].

Diğer taraftan, sosyal sistemlerdeki varlıkların kümelenmeleri, kümeleme analiz metotlarından (Tek bağlantı, Tam bağlantı, Ortalama bağlantı, Kitle merkezi, Wards tekniği) yararlanılarak sosyal bir sistemde varlıkların kümelenmelerinin daha iyi görülmesi sağlanabilmektedir. Bu analiz metotları fizikçiler tarafından korelasyon temelli hiyerarşik yapıların incelenmesinde kullanılmaktadır. İncelenen sistemi oluşturan finansal varlıklar arasındaki hiyerarşik yapıları açıklamada tek bağlantı kümeleme metodunun etkinliği üzerine çalışmalar yapılmıştır [7, 9, 19, 26-28]. Ayrıca, ortalama bağlantı kümeleme metodu kullanılarak finansal varlıkların oluşturduğu küme yapıları belirlenmiştir [29, 30]. Bununla birlikte, son yıllarda zaman serileri (ortalama, karşıtlık, eğrilik, basıklık, normalize edilmiş ağaç 
uzunluğu) [12, 14, 15, 31-33], korelasyon matrislerinin özdeğer ve özvektörlerinin analizi [14, 16, 33-35] gibi istatistik fizik ve uygulamalı matematik yöntemleri kullanılarak Avrupa ve Dünya borsaları, şirketler ve sektörler, faiz oranları ve mal piyasaları çalışılmıştır. Şunu da belirtmemiz gerekir ki, başta, gelişmiş, gelişmekte olan ve gelişmemiş ülkelerin $\mathrm{CO}_{2}$ emisyon değerleri, ekonomik büyümeleri ve elektrik tüketimleri arasındaki ilişkilerin hiyerarşik yapı yöntemleri kullanılarak analiz edilmesi ve sonuçların karşılaştırılması ile ilgili bir çalışma şimdiye kadar, en iyi bilgilerimiz dahilinde yapılmamıştır. $\mathrm{Bu}$ çalışmada, sosyofizik kapsamında 1970 ile 2010 yılları arasında gelişmiş, gelişmekte olan ve gelişmemiş ülkelerin çevre kirlilikleri, ekonomik büyümeleri ve elektrik tüketimleri arasındaki topolojik ilişkiler hiyerarşik yapı yöntemleri [en küçük örten ağaç (minimal spanning tree, MST) ve hiyerarşik ağaç (hierarchical tree, HT)] kullanılarak detaylıca incelenecektir.

\section{Data ve Metot}

\subsection{Data}

$\mathrm{Bu}$ çalışmada incelenecek 25 Avrupa ülkesinin karbondioksit $\left(\mathrm{CO}_{2}\right)$ emisyonu değerleri, ekonomik büyümeleri ve elektrik tüketimleri ile ilgili veriler Dünya Veri Bankasındaki (World Data Bank) veri tabanlarında yer alan bilgiler kullanılarak aşağıdaki analizler yapılacaktır. İncelenecek olan ülkeler, bayrakları ve kısaltmaları Tablo 1'de verilmiştir.

Tablo 1. Yirmi beş Avrupa ülkesi, bayrakları ve bunlara karşı gelen kısaltmaları.

\begin{tabular}{|c|c|c|c|c|c|}
\hline Bayrak & Ülke & Kisaltma & Bayrak & Ülke & Kisaltma \\
\hline 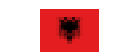 & ALBANIA & ALB & & ITALY & ITA \\
\hline & AUSTRIA & AUT & & LUXENBOURG & LUX \\
\hline & BELGIUM & BEL & & MALTA & MLT \\
\hline & BULGARIA & BUL & & NETHERLANDS & NED \\
\hline 1 & CYPRUS & CYP & & NORWAY & NOR \\
\hline & DENMARK & DEN & & POLAND & POL \\
\hline & FINLAND & FIN & e & PORTUGAL & POR \\
\hline & ENGLAND & ENG & & ROMANIA & ROU \\
\hline & FRANCE & FRA & & SPAIN & ESP \\
\hline & GERMANY & GER & 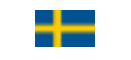 & SWEDEN & SWE \\
\hline 层 & GREECE & GRE & + & SWITZERLAND & SUI \\
\hline & HUNGARY & HUN & c. & TURKEY & TUR \\
\hline 口 & IRELAND & IRL & & & \\
\hline
\end{tabular}

\subsection{En Küçük Örten Ağaç (MST) ve Hiyerarşik Ăgaç (HT)}

Hiyerarşik yapı yöntemleri kullanılarak; başta gelişmiş, gelişmekte olan ve gelişmemiş ülkelerin karbondioksit emisyonu değerlerinin topolojisini elde etmek için bu sosyal sistemlerdeki varlıklar arasındaki senkronizasyon ölçülerek varlık çiftleri arasındaki korelasyon fonksiyonu tanımlanacaktır. Bu sistemlerin her biri için korelasyon bağıntıları hesaplanacak ve o sistemin yapısı ile ilgili bilgiler elde 
edilecektir. Daha sonra korelasyonların özelliklerinin analizlerine bağlı olarak, bu sistemlerin davranışları incelenecektir. İncelenecek sistem için her bir öğenin değerindeki değişim oranı,

$$
R_{i}(t)=\ln P_{i}(t+\tau)-\ln P_{i}(t)
$$

ile tanımlanır ve burada $P_{i}(t)$ i'inci varlığın $t$ zamanındaki değerini, $\tau$ ise kullanılan zaman serisini, gün, hafta, yıl gibi, ifade etmektedir. Denklem (1)'den elde edilecek varlıklar kullanılarak, ülke çiftleri arasındaki korelasyon fonksiyonu,

$$
C_{i j}=\frac{\left\langle R_{i} R_{j}\right\rangle-\left\langle R_{i}\right\rangle\left\langle R_{j}\right\rangle}{\sqrt{\left(\left\langle R_{i}^{2}\right\rangle-\left\langle R_{i}\right\rangle^{2}\right)\left(\left\langle R_{j}^{2}\right\rangle-\left\langle R_{j}\right\rangle^{2}\right)}},
$$

şeklinde tanımlanır ve tanımlanan korelasyon fonksiyonundan yararlanılarak tüm ülke çiftleri arasındaki korelasyonlar hesaplanır. Burada $\left\langle R_{i}\right\rangle,\left\langle R_{j}\right\rangle$ ve $\left\langle R_{i} R_{j}\right\rangle$ notasyonları zaman üzerinden istatistiksel ortalama anlamına gelmektedir. $C_{i j}$ korelasyon katsayısı $-1 \leq C_{i j} \leq+1$ arasındaki değerlere sahiptir ve $C_{i j}=-1$ olduğunda tamamıla zit-ilişkili varlıklar, $C_{i j}=+1$ olduğunda tamamıyla ilişkili varlıklar anlamına gelmektedir. Eğer $C_{i j}=0$ olursa, $i$ ve $j$ varlıkları arasında iliş̧ki yoktur.

$N$ tane farklı ülkenin $\mathrm{CO}_{2}$ emisyonu değerleri verildiğinde, verilen varlıklar arasındaki bütün kombinasyonlar için çapraz korelasyon fonksiyonları hesaplanarak $C_{i j}$ korelasyon katsayıları için $N \times N$ 'lik bir matris elde edilir. Bu matriste, denklem (2)'nin tanımından $C_{i i}=1$ 'dir ve $C_{i j}=C_{j i}$ simetrisine sahiptir. Bu korelasyon matrisini en küçük örten ağacı (minimal spanning tree) (MST) oluşturmak için uygularız ve MST kullanılarak varlıklar arasındaki ağ şebekesini sezgisel olarak (anlamlı bir ilişki ile) kurabiliriz. Normal bir ağaç, çevre içermeyen birbiriyle bağlantılı bir grafiktir ve bir ağaç üzerinde $\mathrm{N}$ tane düğ̈̈m (ülkelerin $\mathrm{CO}_{2}$ emisyonu değeri) ve $N$-1 tane ayrıt (edge) bulunur. Bu yüzden, bir ağaç üzerinde bir düğümden başka bir düğüme gitmek için sadece tek bir yol mevcuttur. MST ise, üzerinden bir grafikteki tüm düğümlere ulaşılabilen ağaçlar içerisinde, toplam ağırlığı en düşük olan ağaçtır. Ayrıt mesafeleri ise aşağıda verilen Öklid mesafesinin üç aksiyomuna uymaktadır:

i) Sadece $i=j$ olduğunda $d_{i j}=0$;

ii) ii) $d_{i j}=d_{j i}$;

iii) iii) $d_{i j} \leq d_{i k}+d_{k j}$.

Burada $d_{i j} i$ ve $j$ ülke çiftleri için metrik mesafeyi göstermektedir. MST'yi kurmak için kurlar arasındaki Öklid mesafelerine ihtiyacımız vardır. Ancak, $C_{i j}$ korelasyon katsayıları bu aksiyomlara uymaz. Bundan dolayı $C_{i j}$ korelasyon katsayıları, ilk kez John C. Gower tarafindan çok değişkenli analizde kullanılan karakteristik kök ve vektör yöntemlerinin bazı mesafe özelliklerini çalışırken ileri sürdüğü [J.C.Gower, 
Biometrica 53(3-4), 325-338 (1966)] ve sosyofizik kapsamında ilk kez Mantegna tarafindan kullanılan varlık çiftleri arasındaki $d_{i j}$ metrik mesafesine aşağıdaki bağıntıyla dönüştürebilir:

$$
d_{i j}=\sqrt{2\left(1-C_{i j}\right)}
$$

burada $d_{i j}$ metrik mesafesi $0 \leq d_{i j} \leq 2$ arasındaki değerlere sahiptir. Küçük mesafeler kurlar arasındaki kuvvetli çapraz etkileşim anlamına gelmektedir. Her bir sistemin ağ şebekesi, incelenen sistemler için oluşturulacak mesafe matrisleri kullanılarak, elde edilir.

Artık $d_{i j}$ 'lerden elde edilen $N \times N$ 'lik matris kullanılarak $N$ tane ülke için MST kurulabilir. Bir grafik üzerinde en küçük örten ağacı tespit etmek için çeşitli algoritmalar (Kruskal, Prim ve Sollins Algoritmaları gibi) mevcuttur. Burada Kruskal algoritmasından yararlanılacaktır ve Kruskal Algoritması, bir grafik üzerinde MST’yi bulmak için izlenilen çözüm adımları ise şu şekildedir:

- Başlangıçta ağacımız hiç ayrıt içermez ve olası tüm dalların uzunlukları hesaplanarak, küçükten büyüğe doğru sıralanır,

- Daha önceden ağaca katılmamış en küçük ağırlıklı ayrıt seçilir,

- Eğer bu ayrıtın ağaca katılması, bir kapalı döngü oluşmasına sebep olmuyorsa ağaca katılır,

- Ağaçtaki ayrıt sayısı (N-1)'e ulaşana kadar ikinci adıma dönülerek işleme devam edilir.

Elde edilen grafik $N$ tane ülkenin bağlı olduğu MST'dir. Ayrıca $d_{i j}$ metrik mesafelerinde yararlanılarak ülkeler arasındaki hiyerarşik ağaçlarda elde edilir. Hiyerarşik sınıflandırmayı yapabilmemiz için Öklid uzayında tanımlı bir ultrametrik mesafeler matrisi tanımlamak gerekmektedir. Bu matrisin tanımlanması için denklem (3) kullanılabilir yada doğrudan elde edilen en küçük örten ağaçlara bakılabilir. Bu durumda ultrametrik mesafe;

$$
d_{i j}^{<} \leq \max \left\{d_{i k}, d_{k j}\right\}
$$

şeklinde tanımlanır ve burada $d_{i j}^{<}$ultrametrik mesafedir. Bu ifade Öklid uzayı aksiyomlarına uymak zorundadır. Bu eşitlikten yararlanılarak ülkeler arasındaki hiyerarşik ağaçlar (HT) elde edilebilir.

\section{Ortalama Bağlantı Kümeleme Analizi}

Ortalama bağlantı kümeleme analizi, hiyerarşik ağaçlardaki küme yapılarını daha iyi gözlemlemek ve incelenecek sistemdeki grupları ayırt etmek için kullanılmaktadır. Bu teknikte, iki küme arasındaki fark, bir küme arasındaki eleman çiftleri ile diğer bir kümedeki eleman çiftleri arasındaki ortalama farkı olarak alınır. Bu analizi; birimleri, değişkenler arası benzerlik ya da farklılıklara dayalı olarak hesaplanan bazı ölçülerden yararlanarak homojen gruplara bölmek belirli prototipler tanımlamak amacıyla kullanılır. $n$ elemanlı bir sistem için $C_{i j}$ korelasyon matrisi olmak üzere ortalama bağlantı kümeleme analizi aşağıdaki adımlarla açıklanabilir: 
1. Korelasyon matrisini $Q=C$ olacak şekilde $C_{i j}$ matris elemanlı bir $Q$ matrisi ayarlanır.

2. $g$ şeklinde $S_{h}$ ve $S_{k}$ gibi farklı bağlı bileşenlere ait elemanlardan arasından maksimum $C_{h k}$ korelasyon seçilir.

3. $C_{u p}=\operatorname{Max}\left\{C_{i j}, \forall i \in S_{h}\right.$ ve $\left.\forall j \in S_{k}\right\}$ olacak şekilde $u$ ve $p$ elemanları bulunur.

4. $\quad C_{u p}$ ağırlıklı $u$ ve $p$ elemanları arasındaki bağ $g$ şekline ilave edilir. $\mathrm{Bu}$ bağ $g$ şekline ilave edildiğinde, $u$ ve $p S=S_{h} \cup S_{k}$ olacak şekilde aynı bağlı bileşene ait olurlar.

5. Böylece $Q$ matrisi yeniden tanımlanabilir:

$$
\left\{\begin{array}{l}
C_{i j}=C_{h k}, \text { ĕger } i \in S_{h} \text { ve } j \in S_{k} \\
C_{i j}=\text { Ortalama }\left\{C_{p t}, p \in S \text { ve } t \in S_{j}, S_{j} \neq S \text { olmak üzere }\right\}, \text { ĕger } i \in S \text { ve } j \in S_{j} \\
C_{i j}=C_{i j}, \text { bunların dişında }
\end{array}\right.
$$

6. Eğer $g$ hala bağlantısız bir şekilde ise ikinci adıma geri dönülür yoksa işlem sonlandırılır.

Sonuçta oluşan grafik, sistemin en küçük örten ağacıdır ve bundan yararlanılarak ülkelerin $\mathrm{CO}_{2}$ emisyonu değerleri, ekonomik büyümeleri ve elektrik tüketimleri arasındaki ilişki hiyerarşik ağaçlarda elde edilecektir.

\section{Sonuçlar \\ 3.1 $\mathrm{CO}_{2}$ Emisyonu}

$\mathrm{Bu}$ kesimde 25 Avrupa ülkesinin karbondioksit emisyonu verileri kullanılarak bu ülkeler arasındaki etkileşmeler 1970-2010 zaman periyodu için incelendi. Bunun için tüm ülkeler arasındaki korelasyonlar ayrı ayrı hesaplandı ve ülkelerin korelasyon matrisi elde edildi. Elde edilen bu korelasyon matrisi kullanılarak mesafe matrisi oluşturuldu. Mesafe matrisinden yararlanılarak en küçük örten ağaç (minimal spanning tree, MST) Kruskal algoritmasıyla elde edildi. 1970-2010 zaman dönemi için elde edilen bu MST Şekil 1'de görülmektedir. Şekil 1'de birbiriyle kuvvetli bir şekilde etkileşen iki temel küme görülmektedir. Birinci kümede ITA (İtalya) ve FRA (Fransa)'nın anahtar ülkeler olduğu ve bu ülkelerin FRA'nın bağlantılı olduğu GER (Almanya), LUX (Luxenburg), BEL (Belçika), NED (Hollanda), FIN (Finlandiya), DEN (Danimarka); ITA'nın bağlantılı olduğu ESP (İspanya), POR (Portekiz), AUT (Avusturya), ENG (İngiltere), IRL (İrlanda) ve SWE (İsveç) ülkeler mevcuttur. Diğer grupta ise GRE (Yunanistan) ve ROU (Romanya)'nın anahtar ülkeler olduğu ve TUR (Türkiye), CYP (Kıbrıs), SUI (İsviçre), MLT (Malta), BUL (Bulgaristan), ALB (Ermenistan), POL (Polanya), HUN (Macaristan) ve NOR (Norveç) gibi ülkeler yer almaktadır. İlk grupta ülkeler diğer gruba nazaran sanayilerindeki gelişmeden dolayı birbiriyle bağlantılıdır. İkinci grup ise birbiriyle genellikle komşu ülkelerdir. 
Akkaya-Deviren Ş.

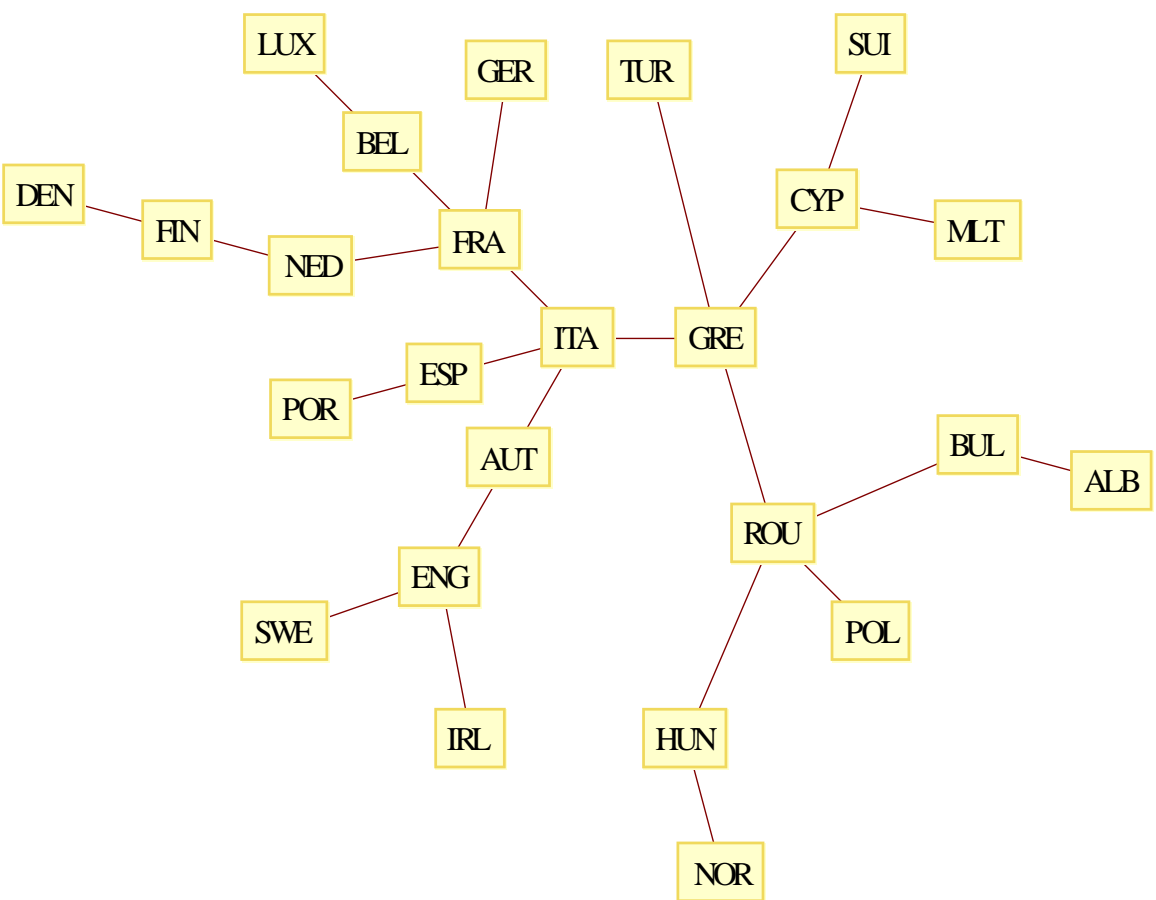

Şekil 1. Yirmibeş Avrupa ülkesinin $\mathrm{CO}_{2}$ emisyonu değerleri için 1970-2010 zaman döneminde elde edilen MST. Kutuların içerinde incelenen ülkelerin uluslararası kısaltmaları yer almaktadır.

Şekil 1'de elde edilen 25 Avrupa ülkesinin MST'sine karşıllk gelen hiyerarşik ağaç (hierarchical tree, HT) Şekil 2'de görülmektedir. Şekil 2 incelendiğinde MST'deki kümelere benzer kümeler olduğu görüldü. Şekilden de görüldüğü gibi ülkeler arasındaki ultrametrik mesafenin en küçük değerde olduğu iki ülkenin ROU (Romanya) ve HUN (Macaristan) olduğu görülür. Bu durum ROU ile HUN'un birbirleriyle yüksek dereceden ilişkili olduklarını gösterirki iki ülkenin birbiyle komşu olması bu durum ile yakından ilişkilidir. Ayrıca ikinci en kuvvetli etkileşmenin FRA (Fransa) ile ITA (İtalya) arasında olduğu gözlenmektedir.

\subsection{Ekonomik Büyüme}

Bu bölümde ise yirmibeş Avrupa ülkesinde kişi başına düşen gayri safi milli hasıla verileri kullanılarak bu ülkeler arasındaki etkileşmeler 1970-2010 zaman periyodu için incelendi. Yine tüm ülkeler arasındaki korelasyonlar ayrı ayrı hesaplanarak, ülkelerin korelasyon matrisi elde edildi ve bu korelasyon matrisi kullanılarak mesafe matrisi bulundu. Mesafe matrisinden yararlanılarak en küçük örten ağaç (minimal spanning tree, MST) Kruskal algoritmasıyla elde edildi. Ülkelerin ekonomik büyümelerinini incelenmesi sonucunda 1970-2010 zaman dönemi için elde edilen bu MST Şekil 3'de görülmektedir. Şekil 3'de elde edilen sonuçlar yapı olarak $\mathrm{CO} 2$ emisyonu değerleri için elde edilen sonuçlara benzemekle birlikte bazı ülkelerin bağlantıları değişmiştir. Buda ekonomik olarak doygunluğa ulaşan bazı ülkelerin sanayileşmenin yanında çevresel etkilere de önem vermelerinden kaynaklanmaktadır. Burada merkezde anahtar ülke olarak FRA ve ESP yer almaktadır; çünkü diğer ülkelerle ençok etkileşim halindeki ülkeler bunlardır. 


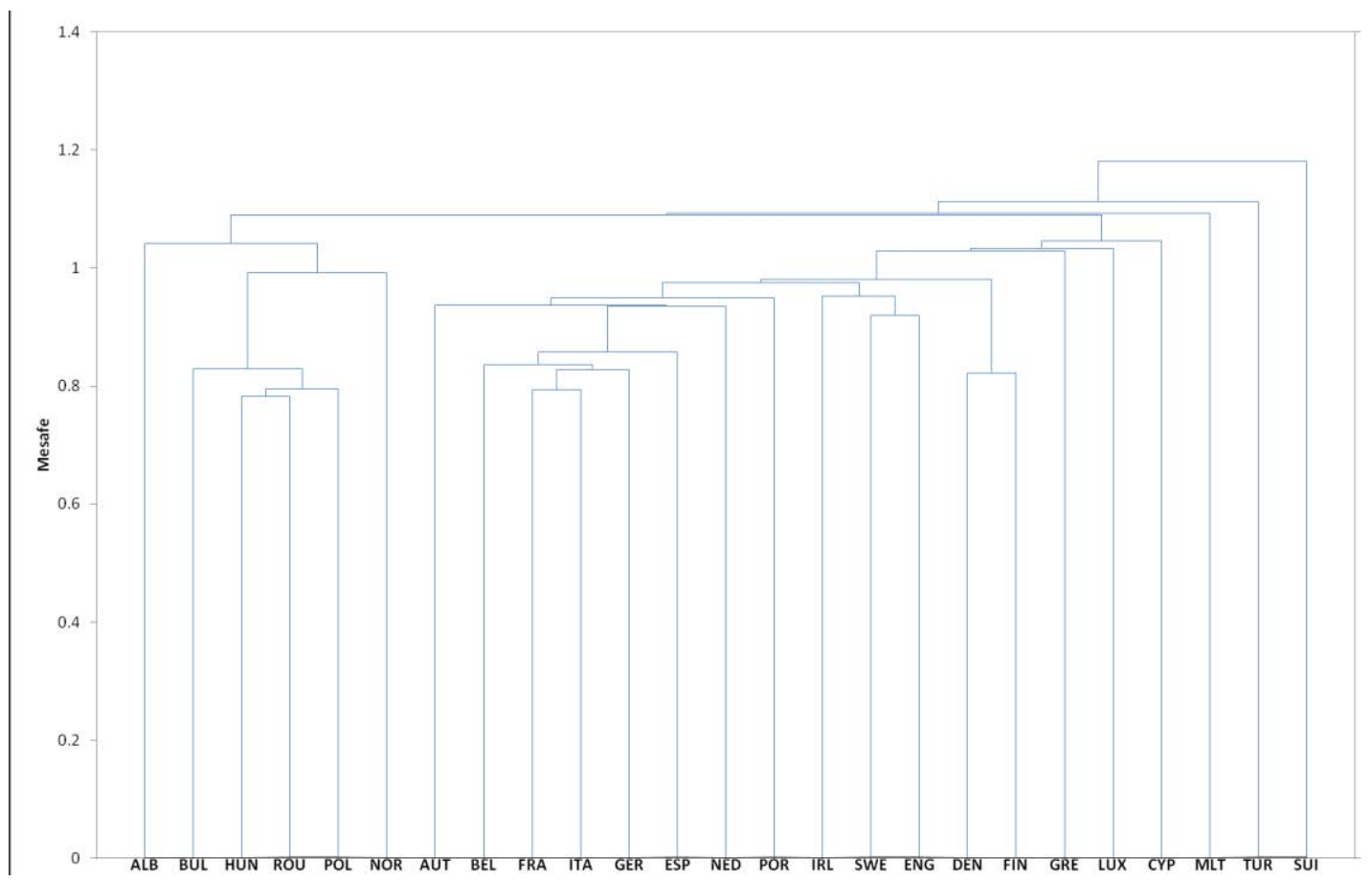

Şekil 2. Yirmibeş Avrupa ülkesinin $\mathrm{CO}_{2}$ emisyonu değerleri için 1970-2010 yılları arasındaki döneminde elde edilen HT. Yatay çizgi ülkeler arasındaki mesafeye karşılık gelmektedir.

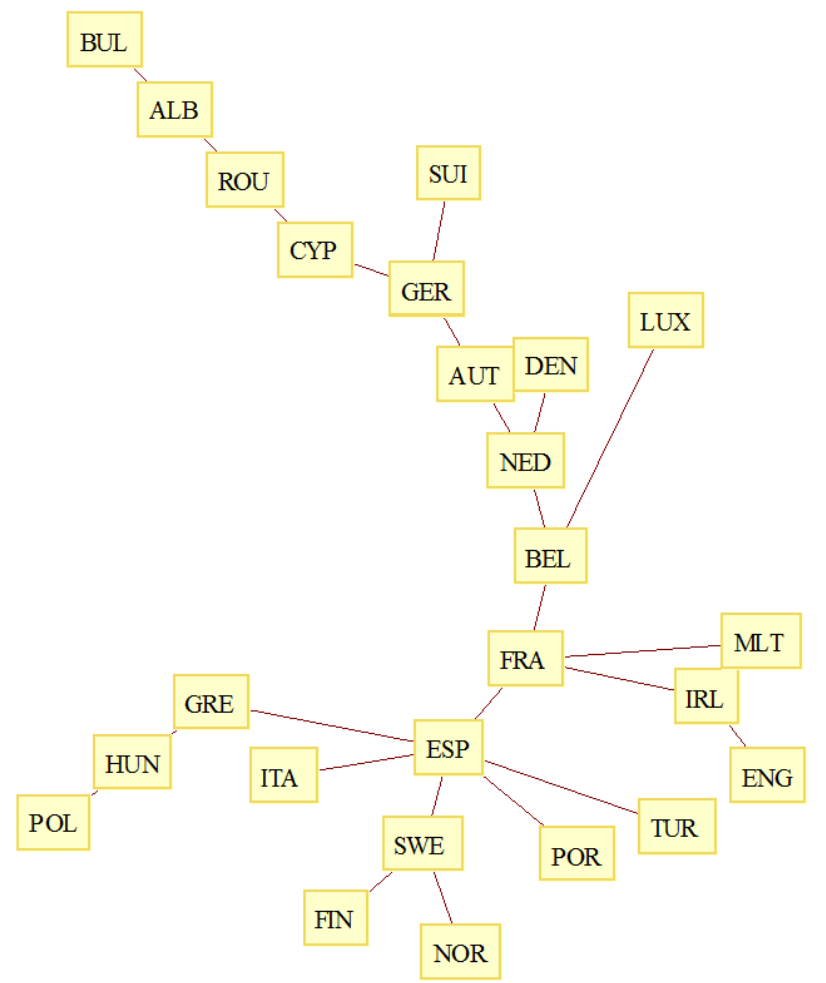

Şekil 3. Yirmibeş Avrupa ülkesinin kişi başına düşen gayri safi milli hasıla değerlerinde 1970-2010 zaman dönemi için elde edilen MST. Kutuların içerinde incelenen ülkelerin uluslararası kısaltmaları yer almaktadır. 
Şekil 3'de elde edilen 25 Avrupa ülkesinin kişi başına düşen gayri safi milli hasıla değerlerinde MST'si ile ilgili olan hiyerarşik ağaç (hierarchical tree, HT) Şekil 4'de görülmektedir. Şekil 4 incelendiğinde MST'deki kümelere benzer kümeler olduğu görüldü. Şekilden de görüldüğü gibi ülkeler arasındaki ultrametrik mesafenin en küçük değerde olduğu iki ülkenin GER (Almanya) ve AUT (Avusturya) olduğu görülür. Bu durum GER ile AUT’un birbirleriyle yüksek dereceden ilişkili olduklarını gösterir ki iki ülkenin birbiyle komşu olması ve ticari, sosyal ve ekonomik yakınlıkları ile doğrudan ilişkilidir. Bu ülkelere sırasıyla NED, BEL, DEN, FRA, SUI, LUX, ESP, GRE, ITA, SWE, POR, MLT, IRL, ENG, FIN ve NOR ülkeleri eklenerek büyük bir grup oluşturmuşlardır. Ayrıca bu grubun içersinde bulunan ve Büyük Britanya'yı oluşturan IRL ve ENG ikili alt grup oluşturmuşlardır.

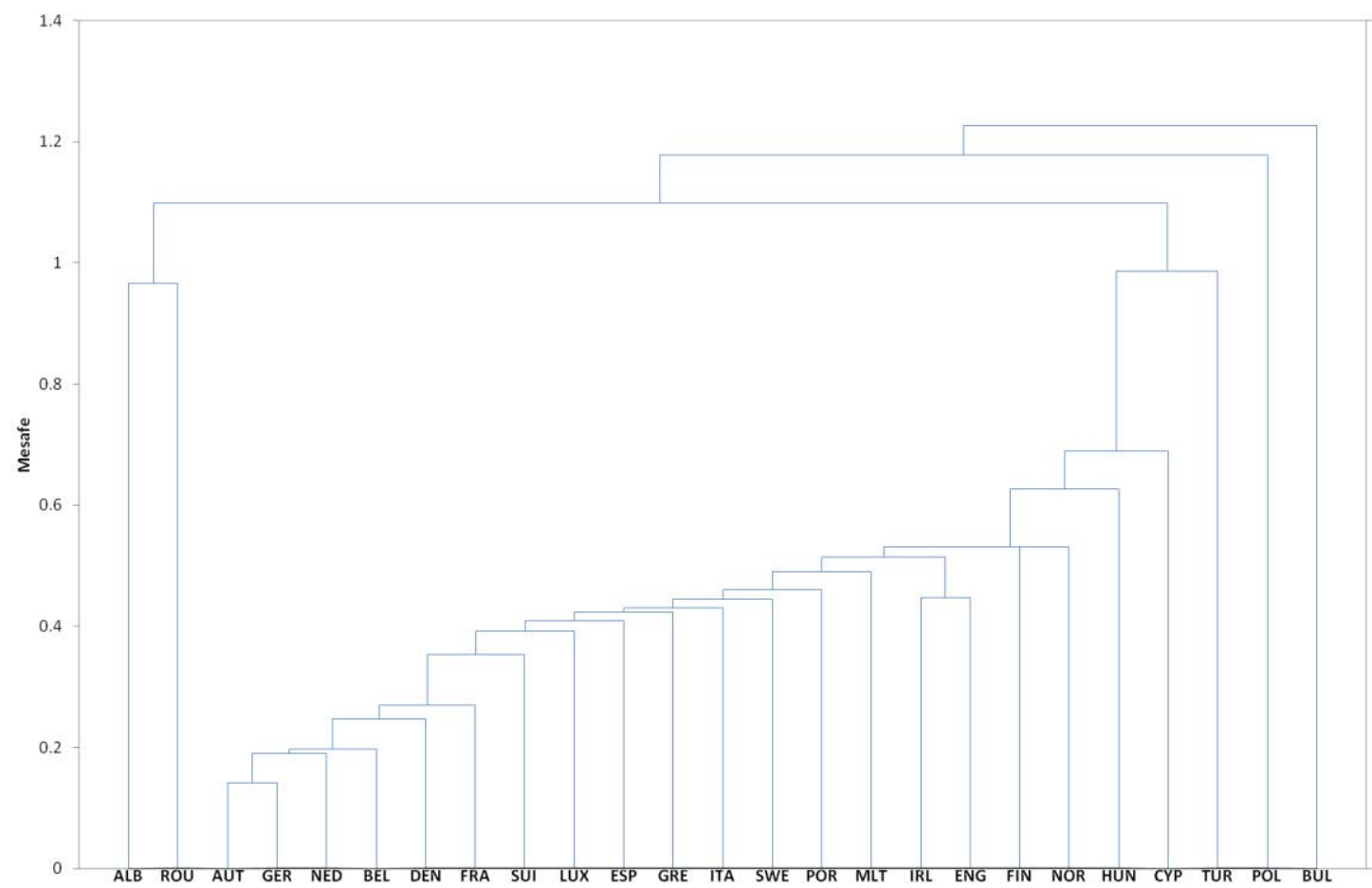

Şekil 4. Yirmibeş Avrupa ülkesinin kişi başına düşen gayri safi milli hassıla değerlerinde 1970-2010 yılları arasındaki dönem için elde edilen HT. Yatay çizgi ülkeler arasındaki mesafeye karşılık gelmektedir.

\subsection{Elektrik Tüketimi}

Bu kesimde yirmibeş Avrupa ülkesinin tükettikleri elektrik verileri kullanılarak bu ülkeler arasındaki etkileşmeler 1970-2010 zaman periyodu için incelendi. Bunun için tüm ülkeler arasındaki korelasyonlar ayrı ayrı hesaplandı ve ülkelerin korelasyon matrisi elde edildi. Elde edilen bu korelasyon matrisi kullanılarak mesafe matrisi oluşturuldu. Mesafe matrisinden yararlanılarak en küçük örten ağaç (minimal spanning tree, MST) Kruskal algoritmasıyla elde edildi. 1970-2010 zaman dönemi için elde edilen bu MST Şekil 5'de görülmektedir. Şekil 5 dikkatlice incelendiğinde diğer MST'lere yapı olarak benzer sonuçlar elde edilmiştir; ancak merkezde yer alan ülkeler yer değiştirerek BEL ve AUT anahtar ülkeler olmuşlardır. Ayrıca ROU, BUL ve ALB ülkeleri küçük bir alt grup oluşturmuşlardır. Bunun sebebi ise bu ülkelerin hem sınır komşuları olmaları hem de sanayileşme olarak birbiriyle yakından ilişki içinde bulunmalarıdır. 


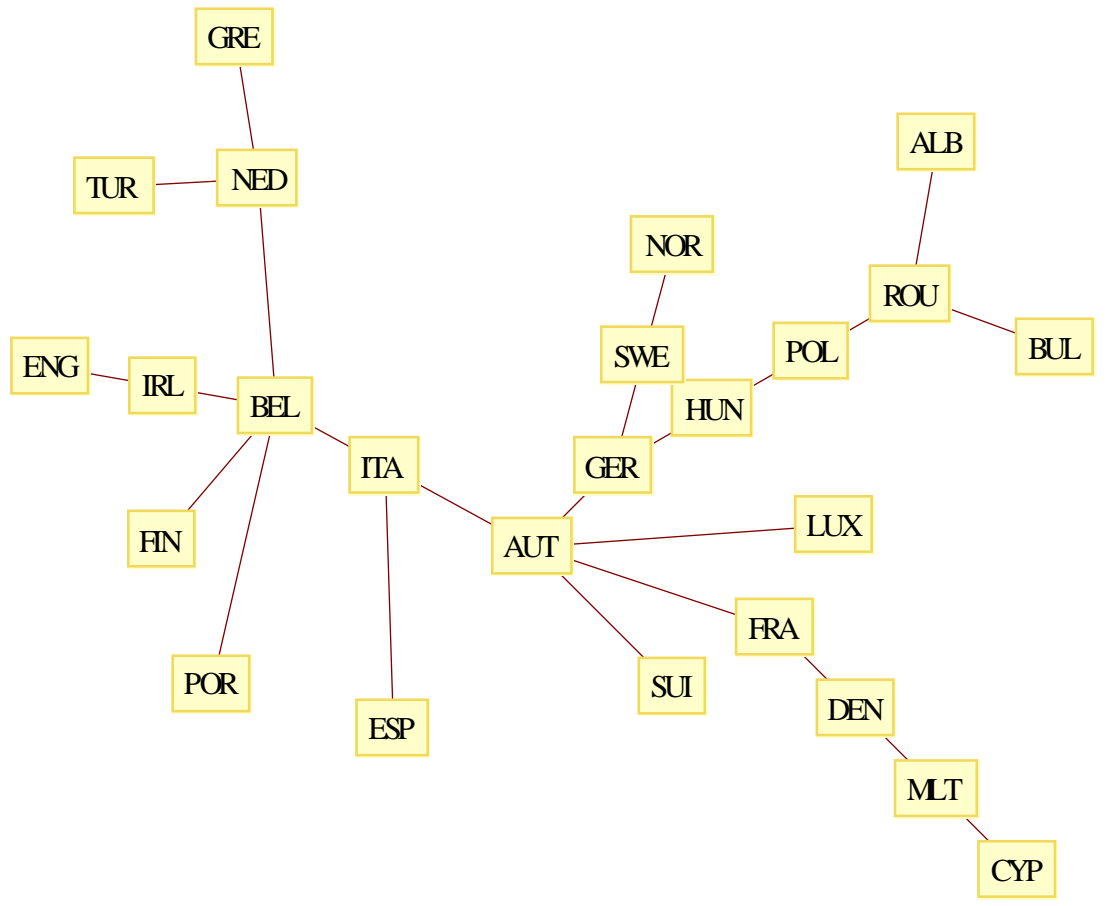

Şekil 5. Yirmibeş Avrupa ülkesinin elektrik tüketim değerleri için 1970-2010 zaman döneminde elde edilen MST. Kutuların içerinde incelenen ülkelerin uluslararası kısaltmaları yer almaktadır.

Şekil 5'de elde edilen yirmibeş Avrupa ülkesinin elektrik tüketimi değerleri için elde edilen MST' sine karşıllk gelen hiyerarşik ağaç (hierarchical tree, HT) Şekil 6'da görülmektedir. Şekil 6 incelendiğinde MST'deki kümelere benzer kümeler olduğu görüldü. Şekilden de görüldüğü gibi ülkeler arasındaki ultrametrik mesafenin en küçük değerde olduğu iki ülkenin BEL ve ITA olduğu görülür. Bu durum BEL ile ITA’nın birbirleriyle yüksek dereceden ilişkili olduklarını göstermektedir. Ayrıca ikinci en kuvvetli etkileşmenin BUL ile ROU arasında olduğu gözlenmektedir. Bu HT'lerdeki ilk kümelenme BEL, ITA, NED, IRL, FIN ve HUN'dir. İkinci kümelenme ise BUL ve POL arasındadır. 


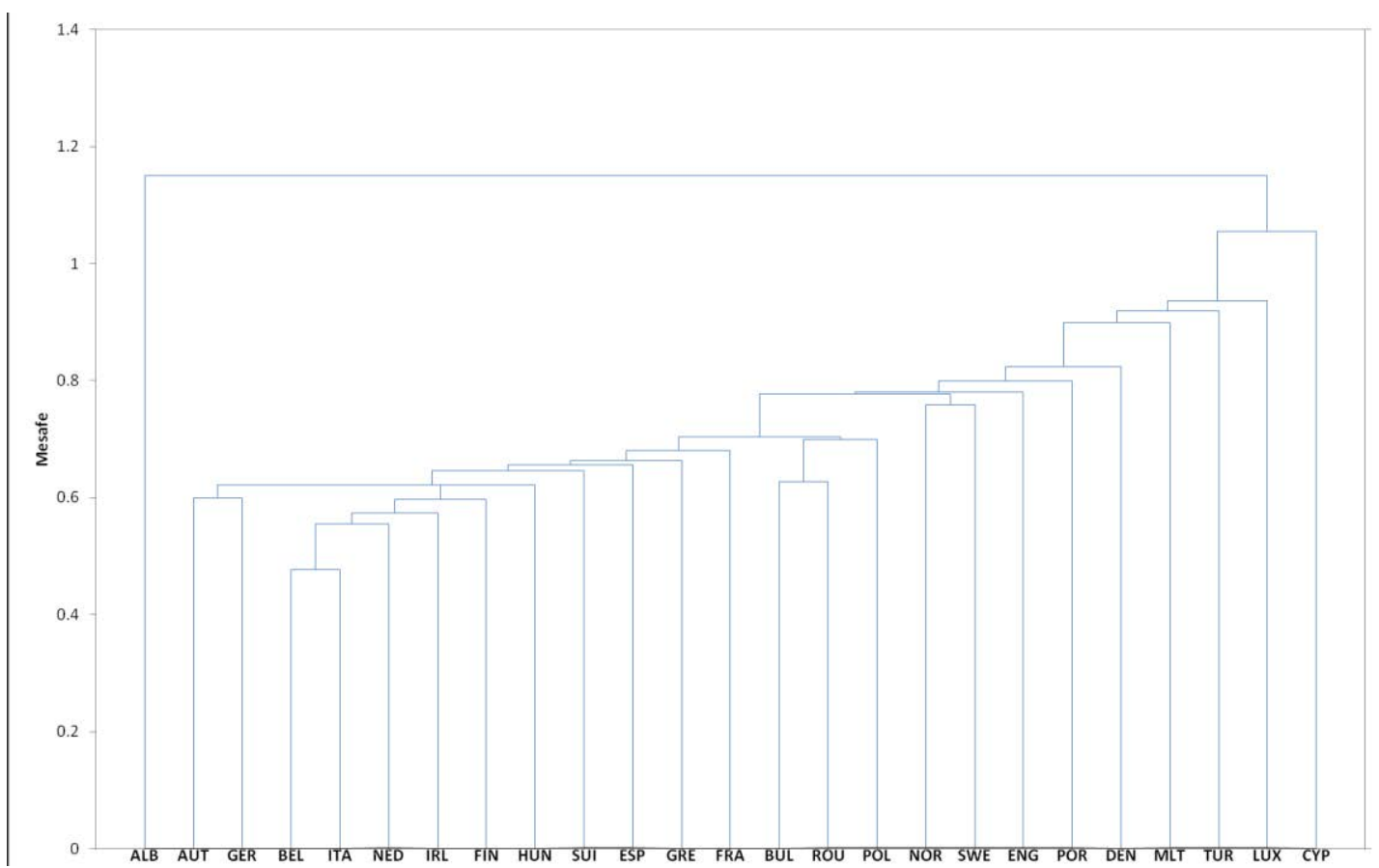

Şekil 6. Yirmibeş Avrupa ülkesinin elektrik tüketimi değerleri için 1970-2010 yılları arasındaki döneminde elde edilen HT. Yatay çizgi ülkeler arasındaki mesafeye karşılık gelmektedir.

\section{4. Özet ve Tartışma}

Bu çalı̧̧ada, 1970-2010 yılları arasında yirmibeş Avrupa ülkesinin karbondioksit emisyonları, ekonomik büyümeleri ve elektrik tüketimleri arasındaki ilişkilerin topolojik analizi, hiyerarşik yapı yöntemleri (en küçük örten ağaç (minimal spanning tree, MST) ve hiyerarşik ağaç (hierarchical tree, HT)) kullanılarak, yapıldı. Bunun için öncelikle tüm ülkeler arasındaki korelasyonlar ayrı ayrı hesaplandı ve ülkelerin korelasyon matrisleri elde edildi. Elde edilen bu korelasyon matrisleri kullanılarak mesafe matrisleri oluşturuldu. Mesafe matrislerinden yararlanılarak çalışılan üç farklı veri seti için en küçük örten ağaç (minimal spanning tree, MST) Kruskal algoritmasıyla elde edildi. Ekonomik, sosyal, çevresel ve jeolojik ilişkilerine ve yakınlıklarına göre oluşturulan MST'lerden ve HT'lerden ülkelerin farklı kümeleri tanımlandı ve ülkeler arasındaki ilişkiler belirlendi. Ayrıca ülkelerin oluşturdukları küme yapıları ve her bir kümedeki anahtar ülke/ülkeler tespit edildi. Bu çalışmadaki yöntem kullanılarak tüm dünya ülkelerinin eğitim düzeyleri, sağlık sektörü, yaşam süreleri, doğum oranları gibi pek çok duruma uygulanabilir.

\section{Teşekkür}

Bu Çalışma NEÜ BAP komisyonu tarafindan NEÜBAP13F37 nolu Proje ile desteklenmiştir.

\section{Kaynaklar}

[1] Callen E., Shapiro, D. A, Theory of Social Imitation, Phys. Today, 23-28, 1974.

[2] Weidlich W., The statistical decription of polarization phenomena in society, Br. J. Math. Statist. Physcol, 24 (1), 251-266, 1971.

[3] Vallacher R. R., Nowak A., Zochowski M., "Dynamics of social coordination: The synchronization of internal states in close relationships”, In P. Hauf \& F. Forsterling (Eds.), 
Making minds: The shaping of human minds through social context (pp. 31-46). Amsterdam: John Benjamins Publishing Company. UW, 2007.

[4] Kulakowski K., Around the Gap between Sociophysics and Sociology (abs), Prepared for the book 'Lectures on Socio- and Econophysics' after the Summer School on SocioEcono-Physics 2007 in Windberg, 2007.

[5] Galam S, Sociophysics: do Humans Behave Like Atoms?, CREA, Paris, November 14-16, 2011.

[6] Galam S. Sociophysics: A Physicist’s Modeling of Psycho-political Phenomena, Claiming the Paternity of Sociophysics, pgs. 61-63. Springer, 2012.

[7] Mantegna R.N., "Hierarchical structure in financial markets”, Eur. Phys. J. B, 11, 193-197, 1999.

[8] Mantegna R.N., Stanley H.E., “An Introduction to Econophysics-Correlation and Complexity in Finance”, Cambridge University Press, Cambridge, 2000.

[9] Bonanno G., Caldarelli G., Lillo F., Mantegna R.N., “Topology of correlation-based minimal spanning trees in real and model markets”, Phys. Rev. E, 68, 046130, 2003.

[10] Zherebtsov A.A., Kuperin Yu. A., Application of self-organizing maps for clustering DJIA and NASDAQ100 portfolios, cond-mat/ 0305330.

[11] Eom C., Oh G., Kim S., “Topological Properties of a Minimal Spanning Tree in the Korean and the American Stock Markets”, J. Korean Phys. Soc., 51, 1432-1436, 2007.

[12] Garas A., Argyrakis P., “Correlation study of the Athens Stock Exchange”, Physica A, 380, 399410, 2007.

[13] Garas A., Argyrakis P., Havlin S., The structural role of weak and strong links in a financial market network, Eur. Phys. J. B 63, 265-271, 2008.

[14] Çukur S., Eryigit M., Eryigit R., “Cross correlations in an emerging market financial data”, Physica A, 376, 555-564, 2007.

[15] Gilmore C. G., Lucey B. M., Boscia M., “An ever-closer union? Examining the evolution of linkages of European equity markets via minimum spanning trees”, Physica A, 387, 6319-6329, 2008.

[16] Sieczka P., Hołyst J.A., "Correlations in commodity markets”, Physica A, 388, 1621-1630, 2009.

[17] Brida J. G., Esteban L. P., Risso W. A., Devesa M. J. S., "The international hotel industry in Spain: Its hierarchical structure”, Tourism Management, 31, 57-73, 2010.

[18] Spada E., Saglioccca L., Sourdis J., Garbuglia A. R., Poggi V., Fusco C. D., Mele A., "Use of the Minimum Spanning Tree Model for Molecular Epidemiological Investigation of a Nosocomial Outbreak of Hepatitis C Virus Infection”, Journal of Clinical Microbiology, 42, 4230-4236, 2004.

[19] Mizuno T., Takayasu H., Takayasu M., “Correlation networks among currencies”, Physica A, 364, 336-342, 2006. 
[20] Naylor M.J., Rose L.C., Moyle B.J., “Topology of foreign exchange markets using hierarchical structure methods”, Physica A, 382, 199-208, 2007.

[21] Keskin M., Deviren B., Kocakaplan Y., “Topology of the correlation networks among major currencies using hierarchical structure methods”, Physica A, 390, 719-730, 2011.

[22] Keskin M., Deviren B., Kantar E., Quantitative Finance, submitted.

[23] Kocakaplan Y., Deviren B., Keskin M., Hierarchical structures of correlations networks among Turkey’s exports and imports by currencies, Physica A, 391, 6509-6518, 2012.

[24] Kantar E., Deviren B., Keskin M., Hierarchical structure of Turkey’s foreign trade, Physica A, 390, 3454-3476, 2011.

[25] Kantar E., Deviren B., Keskin M., Investigation of major international and Turkish companies via hierarchical methods and bootstrap approach, The European Physical Journal B, 84, 339350, 2011.

[26] Kullmann L., Kertész J., Kaski K., Time-dependent cross-correlations between different stock returns: A directed network of influence, Phys. Rev. E, 66, 026125, 2002.

[27] Bonanno G., Vandewalle N., Mantegna R.N., Taxonomy of stock market indices, Phys. Rev. E, 62, R7615- R7618, 2000.

[28] Bonanno G., Lillo F. Mantegna R.N., High-frequency cross-correlation in a set of stocks, Quant. Finance, 1, 96-104, 2001.

[29] Tumminello M., Coronnello C., Lillo F., Miccich`e S., Mantegna R. N., Spanning trees and bootstrap reliability estimation in correlation based networks, Int. J. Bifurcation Chaos, 17, 2319-2329, 2007.

[30] Tumminello M., Lillo F., Mantegna R.N., Correlation, hierarchies, and networks in financial markets, J. Econ. Behav. Organ. 75, 40-58, 2010.

[31] Onnela .J-P., Chakraborti A., Kaski K., Kertész J.,Kanto A., Dynamics of market correlations: Taxonomy and portfolio analysis, Phys. Rev. E, 68, 056110, 2003.

[32] Coelho R., Gilmore C. G., Lucey B., Richmond P., Hutzler S., The evolution of interdependence in world equity markets-Evidence from minimum spanning trees, Physica A, 376, 455-466, 2007.

[33] Junior L. S., Franca L. de Paula, Correlation of financial markets in times of crisis, Physica A 391, 187-208, 2012.

[34] Gligor M. and Ausloos M., Clusters in weighted macroeconomic networks: the EU case. Introducing the overlapping index of GDP/capita fluctuation correlations, European Physical Journal B 63, 533-539, 2008.

[35] Gorski A. Z., Drozdz S., Kwapien J., Oswiecimka, P., Minimal spanning tree graphs and power like scaling in FOREX networks, Acta Physica Polonica A, 114, 531-538, 2008. 